ww w. polisulagos.cl

Doi: http://dx.doi.org/10.32735/S0718-6568/2020-N55-1444

Recibido: 29.11.2019 | Aceptado: 13.01.2020

\title{
Las emociones del comer cotidiano: mujeres entre el asco, la culpa y la vergüenza
}

\author{
Aldana Boragnio \\ Universidad de Buenos Aires / Centro de Investigaciones y Estudios Sociológicos (CIES), Buenos Aires, Argentina. \\ Email: boragnio@gmail.com
}

Resumen: En el presente artículo expondremos las emociones ligadas a las prácticas del comer cotidianas de mujeres empleadas de oficinas públicas de la Administración Pública Nacional Argentina, centrándonos en los aportes teóricos de la sociología de los cs/emociones. El presente trabajo parte de una investigación, en donde se buscaba conocer la configuración de las emociones y las prácticas del comer de dichas mujeres. Para ello se realizaron entrevistas en profundidad a mujeres de entre 22 y 56 años con variedad de años de experiencia laboral en oficinas públicas. Como principales resultados, se observa que el asco, la culpa y la vergüenza se constituyen como las emociones ligadas al comer cotidiano a partir de una articulación entre el régimen alimentario y las prácticas del dietar que organizan el comer.

Palabras claves: Prácticas del comer; prácticas del dietar; privación; empleadas públicas.

\section{The emotions of everyday eating: women between disgust, guilt and shame}

\begin{abstract}
In this article we will expose the emotions linked to the daily eating practices of women employees of public offices of the Argentine National Public Administration, focusing on the theoretical contributions of the sociology of bodies/emotions. The present work is based on a research, where the aim was to know the configuration of emotions and the eating practices of these women. In order to do so, in-depth interviews were carried out with women between 22 and 56 years old with a variety of years of work experience in public offices. The main results were that disgust, guilt and shame are the emotions linked to daily eating, based on an articulation between the diet and the dietary practices that organize eating.
\end{abstract}

Keywords: Eating practices; dieting practices; deprivation; public employees.

\section{As emoções da alimentação cotidiana: mulheres entre nojo, culpa e vergonha}

Resumo: Neste artigo, exporemos as emoções ligadas às práticas alimentares diárias de mulheres empregadas em cargos públicos da Administração Pública Nacional Argentina, enfocando as contribuições teóricas da sociologia dos corpos / emoções. O presente trabalho é baseado em uma investigação, na qual queríamos conhecer a configuração das emoções e práticas alimentares dessas mulheres. Para isso, foram realizadas entrevistas em profundidade com mulheres entre 22 e 56 anos de idade, com vários anos de experiência profissional em cargos públicos. Como principais resultados, observa-se que nojo, culpa e vergonha são constituídas como emoções ligadas à alimentação diária a partir de uma articulação entre a dieta e as práticas alimentares que organizam a alimentação.

Palavras-chave: Práticas alimentares; práticas de dieta; privação; funcionárias públicas.

\section{Introducción: cuerpos/emociones que comen}

Preguntarse por el lugar de las emociones en la vida humana tiene una extensa trayectoria, desde la filosofía de Aristóteles, pasando por los teóricos clásicos y la conformación de la Sociología de las emociones. 
Mientras que algunos autores igualan los conceptos de sentimientos y emociones, pero diferencian los modos de sentir (Ryle, 1971), otros autores los distinguen al definir a las emociones como reacciones específicas que se producen a partir de la interpretación y del etiquetado de eventos cognitivamente (Schachter y Singer, 1962).

Si bien las emociones son trabajadas por diversas disciplinas, hay un consenso de que son «discretas en especie y adaptativas» (Von Scheve y Slaby, 2019, p.4). Por ello, se vuelve axial que «más allá de los conceptos de los desarrollos sociológicos sobre las emociones» las sensaciones o los sentimientos, se centren en la interacción social junto a la experiencia subjetiva, ya que las emociones son

«una experiencia corporal viva, veraz, situada y transitoria que impregna el flujo de conciencia de una persona, que es percibida en el interior de y recorriendo el cuerpo, y que, durante el trascurso de su vivencia, sume a la persona y a sus acompañantes en una realidad nueva y transformada -la realidad de un mundo constituido por la experiencia emocional.» (Denzin [1984] en Bericat, 2012, p.2)

Esto indica que las emociones se caracterizan por ser configuraciones específicas de experiencias, a la vez que tienen un propósito, ya que al significar algo para el sujeto, se puede reflejar en un compromiso evaluativo. Por lo tanto, las emociones deben ser consideradas en «un campo conceptual integrado que abarca el afecto, la emoción y el sentimiento» (Von Scheve y Slaby, 2019, p.12). Precisamente, afectos, pasiones, sentimientos, emociones, son todos significantes que se ligan a iguales o similares cuestiones. Pero lo importante es que el mundo afectivo constituye el eje esencial en el estudio de los cuerpos y las emociones.

Los cuerpos, aunque pueden aparecer en diversos trabajos teóricos como un campo diferente a las emociones, se encuentran conectados ineludiblemente a estas, pues «la condición humana es una condición corporal» (Le Breton, 2017, p.2). En este sentido, acercarnos a las emociones desde una Sociología de los Cuerpos/Emociones se vuelve imprescindible, de modo que en la relación entre los fenómenos sociales y las conductas individuales se encuentra el cuerpo, su constitución y su reproducción, que constituyen un entramado indispensable de los regímenes de estructuración social.

Por otra parte, sabemos que los cuerpos existen en conexión con el entorno/ambiente, y esto a partir de los procesos que se dan en la interacción entre el cerebro, el sistema nervioso central y la distribución de energías que modelan las potencialidades de los estados de vida posibles de los sujetos como agentes sociales (Scribano, 2012). Pero, en tanto la energía corporal se vincula directamente con los nutrientes, sin nutrientes no habrá energía corporal, por lo cual a mayor deficiencia nutricional menor posibilidad de acción. Por ello,

«si la alimentación no contiene nutrientes con el valor energético suficiente y necesario que permita extender la vida más allá de la mera reproducción física, existe un volumen expropiado de dicha energía que es acumulado (y distribuido) diferencialmente (por y para algunos).» (Scribano y De Sena, 2016, p.117)

Se vuelve necesario remarcar la conexión entre la disponibilidad de recursos alimentarios, que altera las cantidades y las calidades energéticas que cada individuo tiene a disposición, permitiendo a esos cuerpos su reproducción y su disponibilidad social. Por lo cual, la posibilidad y la potencia para planear y ejecutar el movimiento y la acción estará condicionada por la disponibilidad de energías.

Al hablar de alimentación estamos refiriéndonos a los cuerpos que comen, a cuerpos/emociones que necesitan los nutrientes básicos para la producción y la reproducción de sus energías corporales, con el fin de «conservar el estado de cosas «naturales» en funcionamiento sistémico» (Scribano, 2010a, p.8) -al que llamamos cuerpo. Y esto, debido a que la energía social se conformará en base a la energía corporal a partir de los procesos de distribución de la misma, como condición de la acción.

Por otra parte, la alimentación está directamente conectada con

«las posibilidades de presentación social de la persona (cuerpo imagen) con las potencialidades para experimentar el mundo (cuerpo piel) y con las capacidades para desplazarse/hacer en el mundo social (cuerpo movimiento)» (Scribano, 2012, p.104) 
siendo estas interacciones claras indicadoras de la dominación social. Por ello, se vuelve esencial centrarse en la conexión orgánico/cognitivo/afectivo «que hilvana la fuerza viva de los músculos con la potencialidad creativa/productiva del cerebro y sus conexiones, [que] es visto como central en la estructuración social» (Scribano, 2016, p.33).

Con base en lo expuesto hasta aquí, en estas páginas presentaremos un análisis sobre los estados afectivos y las emociones ligados al comer de las mujeres empleadas de oficinas de la Administración Pública Nacional ubicadas la Ciudad de Buenos Aires. En la investigación que dio lugar a este artículo, la sociología de los cuerpos/emociones fue la propuesta teórica que nos permitió posar la mirada sobre la implicación mutua entre los cuerpos y emociones, ya que los cuerpos se observan situados en emociones. Por ello, se presenta la barra, que implica la intención de separar/unir, de dar distancia/proximidad y posibilidad/imposibilidad a los objetos/discursos y a los cuerpos/emociones, que han sido pensados como subcampos disciplinares separados y específicos pero que en realidad se encuentran cercanos e interrelacionados (Scribano, 2012).

Los datos que presentamos fueron construidos a partir de entrevistas en profundidad. Se realizaron 24 entrevistas a mujeres empleadas de un Organismo Nacional, de entre 22 y 56 años y con una antigüedad laboral desde los 6 meses a los 23 años. Para el análisis conformamos 3 grupos específicos: 1) «administrativas»: mujeres que llevaban adelante puestos de trabajo administrativo, 2) «profesionales»: mujeres con estudios universitarios completos y que trabajen en puestos relacionados a su profesión, y 3) «jóvenes»: menores de 30 años con puestos administrativos o profesionales, sin hijos y que vivían de modo independiente.

La estrategia de presentación será la siguiente: a) expondremos las categorías principales de las prácticas del comer cotidianas en torno al comer y al régimen alimentario, b) presentaremos las ideas en torno a las prácticas del dietar y la privación, c) desplegaremos las emociones de las entrevistadas, que se centran en el asco, la culpa y la vergüenza y su conexión con las prácticas del comer y d) realizamos un cierre que articula el análisis presentado.

\section{Las prácticas del comer cotidianas: entre la comida de oficina, la dieta y la privación}

En la investigación pudimos conocer que la mayoría de las mujeres entrevistadas desayunan y almuerzan dentro de la oficina y que sus menús cotidianos se organizan entre ensaladas, sándwiches y tartas, siendo el mate y las galletitas los productos que acompañan toda la jornada (Boragnio, 2019a). Como segundo eje, observamos que comen rápido, sin tiempo y en el escritorio, lo que implica que las trabajadoras lleven adelante el acto de comer en un ámbito de trabajo donde lo que prima es el espacio de trabajo, el mobiliario de trabajo y las actividades de trabajo, no del comer, configurándose una «comensalidad descartable»(Boragnio, 2018).

En trabajos anteriores desarrollamos que las prácticas del comer en la oficina se configuran a partir de la trilogía «pesado, liviano, rápido» (Boragnio, 2018; 2019a). Lo pesado y lo liviano se conectan como anversos del comer en la oficina, a partir de comidas livianas que eviten la pesadez de la digestión. Para ello se eligen comidas «rápidas», que lo son en relación a su digestión, al consumo y al formato, presentando una marcada liviandad a nivel de nutrientes y energías corporales. A la vez, la comida de oficina se estructura desde una comensalidad descartable que se conforma a partir de un régimen basado en la comida «rápida y liviana» como modo de evitar la pesadez digestiva y como estado del cuerpo-en-la-oficina. Por otra parte, en este el contexto, la comida de oficina se organiza a partir de ser «rápida, liviana y sin olor», en un régimen que se repite, conformando un comer que es «siempre igual» ${ }^{1}$, en tanto la variedad de la comida elegida, los sabores que estas tienen, los lugares donde comprar son siempre iguales.

Pero al incorporar al análisis a la alimentación cotidiana por fuera del ámbito laboral, se presentan nuevas categorías. Así, observamos que el régimen alimentario se centra en la trilogía «sano, liviano, rico», en donde lo rico es la búsqueda del placer, del gusto y la explicación de lo que se come. Lo sano, implica tanto la búsqueda de comer verduras y tomar agua, como la restricción alimentaria centrada en los hidratos de carbono, no consumir azúcar o consumir productos light. 
Para lograr y mantener este régimen alimentario, algunas mujeres acuden al nutricionista para poder darles comida saludable a su núcleo familiar.

«Con el incentivo de querer que mis hijos coman mejor, que se lleven al colegio snacks, dentro de lo que son los chicos lo más variado posible, fuimos a una nutricionista y le transmitimos esta preocupación y, más o menos, ahí siento que me empecé a ordenar.» (3prof-36 años)

Entendemos la necesidad de las mujeres entrevistadas de ir al nutricionista para aprender a comer, en tanto la pérdida del conocimiento en relación a las prácticas del comer se da a partir de múltiples factores de la Modernidad Alimentaria (Gracia Arnaiz, 2005).

Por otra parte, algunas mujeres acuden con la finalidad de bajar de peso.

«P: ¿ fuiste a un nutricionista? / R: Estoy yendo, sí. (...) la idea es, si logro cambiar el hábito de la comida, eh... puede llegar a mantenerme... o sea, me va a cambiar el metabolismo y mantenerme por más tiempo, digamos, el peso. Sin necesidad de andar haciendo constantemente dieta.» (3adm- 54 años)

En relación a la dieta, casi la totalidad de las mujeres entrevistadas dijeron haber hecho dieta en algún momento de su vida y varias incluso comentaron estar «haciendo dieta» en ese momento. La dieta es llevada adelante por dos motivos, para bajar de peso o como modo de buscar un cambio de hábito que permita mantener una alimentación saludable. Estas prácticas se encuentran ligadas al control del cuerpo (Germov y Williams, 1996), pero son algo más que un «policiamiento» de lo femenino. Si bien, los procesos de consolidación de la imagen belleza-delgadez como obligación es un proceso que ha tenido influencia sobre toda la sociedad occidental a partir de finales del siglo XIX (Vigarello, 2011), claramente recae con mayor presión sobre las mujeres ante el mito de la belleza como una cualidad universal y posible (Wolf, 1990).

Esto se observa porque las entrevistadas que dijeron no ir a la nutricionista o las que no hablaron de ello, también dijeron estar llevando adelante algún régimen alimentario, principalmente un proceso de cambios de hábitos o de prácticas ligadas al control alimentario.

«P: ¿Estás haciendo dieta? / R: No, nunca hago dieta, nunca pude tampoco, igual a ver, inconscientemente siempre me cuido, porque por ejemplo trato de poner el azúcar en nada (...) trato de comer la mayor cantidad de productos light (...) y nada, sí, me cuido (...) sí, siempre estoy como cuidándome o tratando de cuidarme, siempre tengo eso lo de 'bueno, no hay que engordar en la cabeza', pero no como esas minas que se ponen a hacer dieta y comen súper sano no, porque a ver, yo como sándwich de miga todas las semanas, como que no tengo ese poder de voluntad de que están comiendo helado y diciendo 'me estoy cuidando', yo si hay helado como, si hay chocolate como, si hay pizza como, ¿entendés? Después capaz tomo el café sin azúcar, pero no, dieta no.» (1jov- 27 años)

Etimológicamente, la palabra dieta está ligada tanto a la comida indicada por médicos como a la comida cotidiana y a su restricción. En la actualidad, la dieta se apoya en el trípode medicina/cotidianeidad/privación. ${ }^{2}$

El comer como acto cotidiano es una práctica privada, ligada inicialmente a lo doméstico y familiar. A la vez, es una práctica privada en tanto indica una elección particular y personal de cada individuo, al igual que es privada la elección de realizar una dieta y las emociones que se experiencian al llevarla adelante. Pero al mismo tiempo que la dieta es privada es privativa, en tanto que «causa privación o la significa» (RAE) y la privación es la «acción de despojar, impedir o privar» como «la renuncia voluntaria a algo». Por su parte, «privar» tiene como primera acepción «despojar a alguien de algo que poseía», lo cual nos indica que es una acción que hace otro y que es sobre algo, pero, en su vertiente pronominal, privar puede ser un acto personal en donde se «deja voluntariamente algo de gusto, interés o conveniencia».

A partir de los dichos de las entrevistadas pudimos observar que las mujeres no solo están «haciendo dietas», sino que llevan adelante prácticas del dietar, entendiendo a estas como prácticas normativizadas ligadas a la restricción, prohibición, abstinencia y, finalmente, a una privación hedónica (Katz, 2010). De este modo, 
entendemos que en la privación en el comer, ${ }^{3}$ como un acto privado, las mujeres se privan de lo que les gusta como estructura de la práctica del comer. En este sentido, como indica Scribano,

«También es cierto que los procesos de abstinencia y ahorro ascético han atravesado la entera historia del capitalismo y que sus reversos, como la transgresión y el despilfarro, han ocupado también un lugar central en su reproducción. En la situación actual es la estructura sacrificial en tanto forma la que cobra relevancia. El sacrificio no ya como esfuerzo individual/colectivo para vencer la escasez, ni como parámetro para los intercambios recíprocos es puesto en el centro de la escena de la vida cotidiana como rito por el cual se enhebran expiación de culpas, participación mística en/de la totalidad y muerte.» (2013, p.18)

En esa línea de pensamiento, G. Simmel sostenía que «el sistema de relaciones sociales del capitalismo se asentaba en el marco de un intercambio equivalente de sacrificios donde la lógica de la abstinencia producía y reproducía el orden social» (Simmel, 1900, en Scribano, 2010b, p.32). Así, las relaciones sociales tenían como máxima normativa la abstención del disfrute, en pos de alcanzarlo en el futuro.

Siguiendo la argumentación, entendemos que el sacrificio es el sentimiento que anida en las relaciones y estructura las acciones de los individuos a partir de la privatización de las pasiones y el cálculo emocional como base de la vigilancia social y el auto-control. La disciplina y el ahorro ascético conectan las estructuras del sistema capitalista neo-colonial, conformando sensibilidades asociadas mediante el sacrificio.

\section{El círculo del cuidarse: las prácticas del comer entre el gusto y el cansancio}

Como dijimos anteriormente, mientras algunas de las entrevistadas acuden al médico nutricionista para bajar de peso o para «aprender a comer», quienes no hacen dieta dijeron estar «cuidándose», lo cual implica llevar adelante algunas privaciones en torno a la alimentación cotidiana. A la vez, la repetición de la privación lleva a las mujeres al cansancio de la comida y de los sabores (Boragnio, 2019a). Como nos dice una entrevistada

«Los lugares que frecuento son bastantes básicos, los que tienen comida más elaborada es como excepcionalmente que la como, porque me quiero dar el gusto porque me pudrí de comer lechuga, me pudrí de comer sándwich o tartas que no quiero más y digo bueno: «Hoy me compro un plato de comida», pero es la menor cantidad de veces.» (2prof-38)

Este fragmento nos permite observar que la comida como alimento que satisfaga y dé placer aparece como la excepción ante el cansancio de la comida cotidiana organizada a partir de las categorías del régimen alimentario y de las prácticas del dietar. Las mujeres entrevistadas hicieron hincapié en que ponen en práctica diversos recursos para no cansarse de lo que comen, para intentar no «pudrirse».

En la oficina la repetición de la comida es parte de la estructura de la misma, pero la alimentación del hogar tampoco es variada, ya que, al hablar de la comida en el ámbito doméstico, el cansancio de lo que se come vuelve a aparecer como eje. Aunque sean ellas quienes deciden qué comer y quienes cocinan, la comida no varía, es siempre «lo mismo»; por ello, «un plato de comida» aparece como la excepción a la cotidianeidad y el gusto como la búsqueda del placer que le dé sentido a la elección. Si el «plato de comida» aparece como la excepción, el gusto propio asoma no solo pocas veces, sino que lo hace como algo esporádico. Una entrevistada que nos dijo que se estaba cuidando, nos detalla:

«Cocino para mi nena que come de todo, para mi marido que está a dieta y yo picoteo un poco de todo.» (3jov-28 años)

Por otra parte, al mismo tiempo que nos hablan del cansancio de la repetición que las lleva a la saturación (Boragnio, 2018), aparece el cansancio como estado del cuerpo, en relación a la insuficiencia de nutrientes y energía que tiene el comer cotidiano.

«Y después físicamente me pasa que siempre estoy como muy cansada y todo el mundo me dice: 'lo que 
pasa es que no comés los nutrientes que deberías comer a la vida que llevás’ entonces es como que, igual tengo veintisiete años, tampoco es que es una crisis, digamos, del todo, no es que, soy una súper deportista entonces tenés que tener, nada.» (2jov-27 años)

Las entrevistadas ubican al comer como una práctica necesaria, de placer y de disfrute, de la cual se privan. Pero, al mismo tiempo, ésta aparece como una práctica a la cual pueden obviar o transitar a partir de un «picoteo» de comer «cualquier cosita».

Las prácticas del comer, entre el dietar y el cuidarse, aparecen en las mujeres entrevistadas como prácticas de sacrificio y de auto-control que comienzan de modo privado y que ordenan e intervienen la vida cotidiana por completo (Boragnio, 2019c). La privación no es solo una práctica que llevan adelante las mujeres que hacen dieta ligada al descenso de peso, sino que las entrevistadas se autoimponen la privación de lo que les gusta como un modo de «cuidarse». De este modo, las prácticas del comer de las mujeres entrevistadas «se estructuran a partir de una privación auto-infligida que se vuelve pauta moral» (Boragnio, 2019b, p.108). Y, es en esta privación auto-infligida, que las prácticas del sentir se centran en el cansancio, la falta ${ }^{4}$ la repetición, conformando un «círculo del cuidarse».

El «círculo del cuidarse» instaura prácticas del comer a partir de la interconexión entre el cansancio y la falta, ya que la búsqueda de mantener el régimen alimentario -organizado en lo sano, liviano, ricod encuentra el límite en la falta de la imposibilidad de llevar adelante la totalidad de las pautas del régimen. Como anverso de mantener el régimen, el gusto se satura en la repetición de las comidas, los sabores y las pautas, quedando las mujeres privadas del gusto y de las energías necesarias.

\section{Las emociones del comer cotidiano}

A continuación, presentaremos las emociones que las entrevistadas tienen en relación a las prácticas del comer cotidianas. Antes es importante remarcar que estas se presentaran diferenciadas a modo analítico, pero se configuran en una banda mobesiana en donde se superponen y mezclan en el proceso mismo de su configuración y reproducción.

\section{El asco}

El asco den la literatura anglosajona denominado disgustd no es solo una conducta fisiológica ligada al sentido del gusto, aunque éste es parte de su constitución, sino que es una emoción ligada al desagrado y que marca las fronteras de lo que debe ser evitado y separado (Figari, 2009; Rozin, Haidt y McCauley, 1999). En este sentido, el asco se relaciona con los «sentimientos de repulsa, como el displacer, odio, disgusto» (Kolnai, 2013, p.34). Esta emoción se encuentra ligada al desagrado, la repulsión y la aversión, existiendo una íntima relación entre ellos, al punto que el asco puede ser considerado un grado más intenso del desagrado que se encuentra ligado directamente a la corporalidad (Ibid), pero apareciendo ante un peligro espiritual (Salles, 2010).

La experiencia del entramado asco/desagrado/disgusto deja en un estado de alarma y emergencia a la persona que lo siente, en una tensión a partir de la auto-conservación que cuestiona el ser (Menninghaus, 2003), por ello, la persona busca expulsar sí lo que genera esta emoción, poniéndolo por fuera. En este enroque el rechazo puede ser puesto sobre un objeto externo como sobre el propio cuerpo.

De la investigación surgió que el cuerpo aparece como un objeto convertido en recipiente que se encuentra por fuera de la persona misma y, la Lógica del Desecho extiende sus lógicas en la interacción con otros como con el sujeto mismo (Boragnio, 2018). Así, algunas mujeres entrevistadas sienten asco y desagrado sobre su cuerpo -externo, por fuera y ligado al desecho» en relación a su cuerpo imagen.

«P: ¿fuiste a un nutricionista? / R: Fui porque ya estaba, obviamente, que no me podía ver, no me soportaba mirar, no me gustan, o sea, ya ni me miraba en el espejo, así que no, y está bueno, está bueno.» (3adm-54 años) 
La entrevistada «no soportaba mirar(se)» ya que la imagen traspasaba la frontera de lo soportable. El asco/desagrado ante el cuerpo imagen hace que la entrevistada no pueda verse, centrando la emoción del asco en «el deseo de ser el tipo de persona que uno no es» (Nussbaum, 2004, p.102). En este sentido, el cuerpo imagen ubicado en el lugar de recipiente, que muestra la realidad de la tentación al comer, se articula con el cuerpo individual mostrando la materialidad del «mal-comer». Este no se condice con el cuerpo subjetivo como autopercepción en tanto locus de la sensación vital enraizada en la experiencia de un yo y el cuerpo social que se configura desde una ideología del hambre (Bordo, 1993), que se reproduce sin energías suficientes. El asco tiene carácter de respuesta relativo a las impresiones, que se relaciona con el desagrado y la incomodidad.

A la vez, la Lógica del Desecho instancia la relación consigo misma a partir del consumir y desechar. Así, el cuerpo piel se articula con el cuerpo imagen, ubicándose más cerca del desecho y, por lo tanto, del asco. El asco es una emoción paralizante que lleva al escape, por ello, la mujer no mira, repulsa la imagen del cuerpo apartando temporalmente el objeto. El objeto del desagrado queda expuesto por fuera de la entrevistada y el cuerpo subjetivo se desarticula del cuerpo imagen en tanto la persona no soporta mirar, permaneciendo en la encrucijada de afrontar ser o no ser la imagen.

El mirar(se) no es una acción inocente, carga historias, culturas, sentidos, morales, y construye al mundo a través de ellos. Como remarca Le Breton «visualmente, toda percepción es una moral o, en términos más cercanos, una visión del mundo» (2007, p.70), por ello, el desagrado de no soportar mirar ese cuerpo está ligado tanto a la política de los sentidos como a la política de los cuerpos, al organizar a los mismos en cuerpos mirables y cuerpos que no, cayendo con más peso sobre los cuerpos femeninos. Lo que deja a la entrevistada en la contradicción de ver y ser el cuerpo que no es mirable. A partir de esto, las mujeres accionarán tanto no mirando como llevando adelante nuevas prácticas, que buscarán reproducir el «círculo del cuidarse» a partir de las normas médico-nutricionales o de las prácticas del dietar.

Pero el asco no solo aparece desde el desagrado sino también a partir de lo que en castellano se denomina disgusto. El disgusto está formado por el prefijo dis- «que implica la separación de la palabra que le sigue en múltiples vías» y la palabra gusto, que viene del latín gustus y significa saborear. Ahora, disgusto, significa tanto «sentimiento, pesadumbre e inquietud causados por un accidente o una contrariedad» como «fastidio, tedio o enfado que causa alguien o algo», y «desazón, desabrimiento causado en el paladar por una comida o bebida» (RAE).

El cuerpo individuo, el cuerpo imagen y la alimentación se inhiben e influyen recíprocamente, en una relación dialéctica que da lugar a acciones que se centran en la «libertad» e «individualidad» en la elección de llevar adelante prácticas del dietar. De este modo, el desagrado del cuerpo se une con el disgusto de comer siempre lo mismo en una repetición cotidiana de un régimen alimentario basado en la privación.

«P: ¿Qué es lo que más te gusta comer cuando estás en el trabajo? / R: No sabría decirte. Ahí ya no sabría decirte porque estoy medio podrida de todo. Estoy media podrida, la verdad de todo lo que hay acá alrededor, de todos los lugares donde yo fui, estoy media podrida. Ya no le siento el gusto que le sentía.» (1Prof-56 años)

La repetición de la comida trae aparejado la saturación del gusto que produce el disgusto con la alimentación. El asco se liga a la repetición del disgusto «el no-gusto» como un estado del sentir que lleva a la persona a la podredumbre como característica afectiva de las prácticas del comer. Así, el asco, ligado al disgusto, desagrado del desecho y la podredumbre se encuentra en relación directa con el cuerpo individuo, el cuerpo piel y el cuerpo imagen. Pero, es importante remarcar que este disgusto tiene características propias al estar ligado a la posibilidad de la reproducción de las energías, en este sentido

«el asco sacietario es más importante que todas las variantes del disgusto al tocar u oler un objeto (...) pues el asco sacietario emerge en el lugar del placer mismo, donde hay muy poco o ningún placer presente, sino en realidad un exceso.» ${ }^{5}$ (Menninghaus, 2003, p.37)

El asco se encuentra asociado al exceso (Kolnai, 2013), en este caso, exceso de privación, de repetición, 
del mismo gusto. Al comer siempre los mismos sabores, la repetición cotidiana de la comida se hace sentir a partir del no sentir el gusto, ante esto, las entrevistadas «se pudren». Desde una perspectiva evolucionista, el asco se centra en el rechazo de alimentos como mecanismo de supervivencia a partir de una respuesta automática «de rechazo hacia aquello que puede dañar o infectar» (Rozin, Haidt y McCauley, 1999, p.582). En este caso, la podredumbre ligada al disgusto es lo que desagrada y lo que se busca alejar para no «contagiarse» como característica primordial de «ser lo que se come». Así, entendemos que las mujeres no miren los cuerpos que están «podridos», de comer siempre lo mismo, de no comer un «plato de comida», de estar privándose constantemente.

Pero, el asco, es también «una forma de acceder a la esfera moral desde la base de nuestras motivaciones afectivas» (Quepons Ramírez, 2014, p.182), en este sentido vemos que el asco no es solo una experiencia física sino también moral, con una función valorativa, implicando desagrado y repugnancia, pero también pudor y vergüenza (Figari, 2009). Por ello, entendemos que, como veremos en las siguientes páginas, «el desagrado constituye la contrapartida inseparable de los sentimientos de vergüenza» (Elias, 2009, p.504).

\section{Laculpa}

Para Sigmund Freud, la culpa expresa la consecuencia entre el avance de la civilización y la formación de un super-yo que para formarse sólidamente necesita reprimir progresivamente los deseos como parte necesaria del orden social (1989, p.46). En cambio, y desde la sociología, Anthony Giddens (2000, p.88) indicó que la culpa «deriva de sentimientos de haber obrado mal», por lo tanto, esta emoción depende de una acción, de la transgresión de códigos, de

«...una incapacidad para satisfacer ciertas formas de moral imperativa en la conducta de una persona. Es una forma de angustia que resalta sobre todo en ciertos tipos de sociedad donde el comportamiento social está regido por preceptos morales establecidos...» (Ibid, p.196).

El cambio de época entre ambos autores muestra la variación en la relación entre la culpa y la conciencia vinculadas a la moral ascética. Giddens, hace hincapié en que la culpa ya no se encuentra vinculada a la represión de los deseos sino a su multiplicación. Los sistemas normativos desplazan la culpa como mecanismo de sanción social ante la acción no reprimida para pasar a ser un mecanismo de auto-imposición.

En las entrevistas realizadas para esta investigación la culpa apareció recurrentemente en torno a mantener o no el régimen alimentario como estandarte moral del «cuidarse». Al hablar de su alimentación, las mujeres no se sienten conformes con la misma, principalmente se sienten en falta y con culpa.

«P: ¿Cómo te sentís con tus hábitos alimenticios? / R: Mal, muy mal. ¿Pero cómo me siento anímicamente o físicamente? Anímicamente muy mal porque siempre me siento culpable. Siempre digo «uh, no tendría». Después de pasar, digamos, digo 'uh, no tendría que haber tomado esa cervecita', pero nada, se me pasa en seguida, la realidad es que no me complico con esas cosas. (...) Anímicamente me pasa a veces eso, llegás el domingo y decís: ‘uh, no tendría que haber comido tanto’ ¡Pero el lunes siempre arrancás bien, divina, y el martes estás perfecta! y después se va, digamos, todo otra vez, estropeando todo.» (2jov-27 años)

La culpa aparece durante el fin de semana, que es el tiempo sin privaciones donde las entrevistadas dijeron comer lo que les gusta. Ellas nos cuentan que el viernes la privación alimentaria se pone en suspenso para regresar el lunes acompañada de la culpa, pero con la esperanza de «arrancar bien, divina», aunque se sepa que después se va a ir «estropeando todo» quedando ellas en falta. Como podemos observar, la culpa es una emoción central que surge del «círculo del cuidarse», ya que ellas se cuidan, pero siempre rompen el régimen, se sienten culpables y lo vuelven a comenzar. En este sentido, ellas siempre están llevando adelante prácticas del dietar.

«P: ¿Qué estás intentando cambiar? / R: Y comer más verdura, o sea tratar de sacar un poco las carnes, carne roja sobre todo y comer más verdura; la idea es, si logro cambiar el hábito de la comida puedo llegar 
a mantenerme, o sea, me va a cambiar el metabolismo y mantenerme por más tiempo, digamos, el peso, sin necesidad de andar haciendo constantemente dieta.» (3adm-54 años)

La dieta es un proceso y como tal requiere de un tiempo, pero a la vez siempre se está llevando a cabo, nunca termina, es un repetir constante que necesita ser reiterada continuamente. La dieta no tiene final y la culpa de esto es percibida como propia ya que van «estropeando todo», ante ello la auto-responsabilización aparece como la respuesta inmediata. Ésta es solidaria de la culpa y la privatización como eje central de la mantención del régimen alimentario.

«Siempre, toda mi vida me costó mantenerme. Es mi problema. Es mi problema. Porque cuando yo me organizo y empiezo las dietas, (...) he ido a médicos, he hecho sí, médicos, todas las que vos quieras desde adolescente, pero siempre he adelgazado, más, menos, siempre he adelgazado. El punto es por qué no me mantengo. Y no, porque siempre me pasa lo mismo: a veces tardo más tiempo en engordar y a veces tardo menos tiempo en engordar, pero termino engordando. No zafo yo, no zafa la cadera. Porque por ejemplo adelgacé veintitrés kilos; entonces digo: ‘bueno, me puedo mandar un alfajor’, ese me lleva a un pedazo de pizza, ese me lleva a dos empanadas y así voy desorganizándome.» (1prof- 56 años)

Las entrevistadas no solo están haciendo constantemente dieta, sino que el régimen alimentario ligado a la privatización se configura «desde adolescente», como un proceso en donde «siempre pasa lo mismo»: ellas hacen dieta, adelgazan, dejan de privarse y vuelven a empezar la dieta. Este círculo de repetición « «siempre igual» « las deja en un espacio sin salida, tanto la práctica como su resultado, es su responsabilidad, «su problema». En este sentido, la culpa aparece como la muestra de haber hecho mal las cosas y es por su propia acción que ellas no «zafan», ni ellas ni «la cadera».

La culpa «se halla estimulada por experiencias en las que generan sentimientos de inadecuación» (Giddens, 2000, p.87), revelándose como emoción que depende más del juicio negativo de la propia persona sobre su acción, un juicio en el que hay una percepción de control del acto y, por tanto, seguramente, de responsabilidad en el mismo. Por ello, la culpa deja de ser por la no represión ante los deseos de comer, para ser parte de la autoresponsabilización por la no concreción del régimen alimentario.

«P: ¿Y por qué no cenás a la noche? / R: Porque como desbarranqué (risas), bajé quince o dieciséis kilos y ahora recuperé, esto del frío me mató, ¡me mató! Entonces incorporé hidratos, entonces dije: ‘bueno, de alguna manera tengo que compensar’ y dejé de cenar a la noche.» (3adm-54 años)

La culpa se relaciona con la falta en tanto estar en falta genera culpa, pero lo opuesto a la culpa es la reparación y se lleva adelante mediante acciones específicas (Giddens, 2000). En este caso, las entrevistadas ante la culpa de comer de más, operan a partir de la omisión de lo mismo que les generó culpa y eligen no comer como una acción compensadora que intenta reparar la falta. Al mismo tiempo, la compensación las deja en falta de comida, como una privatización que funciona como castigo auto-impuesto.

La culpa frente a no lograr mantener el régimen alimentario se incrementa en las mujeres que tienen hijos. La doble jornada de trabajo dificulta el hacerse tiempo para hacer todo lo necesario para una vida «sana», a la vez que las responsabiliza por no lograrlo y por la consecuencia que tiene esto tiene en ellas y, principalmente, en la familia (Boragnio y Dettano, 2019). Así, la culpa traspasa el disfrute del fin de semana para abarcar ámbitos de la vida familiar y, la responsabilidad de mantener el régimen alimentario, aparece como una carga que genera culpa. De este modo se fortalece en la cotidianeidad el estereotipo de mujeres-madres que dejan de lado sus deseos y su comer» entregándose al cuidado de los otros.

«Y estoy en este proceso de cambio, o sea realmente venia, estábamos medios desbarrancados digamos y nos sentimos mejor, te digo porque fue a nivel inquietud familiar digamos, si bien yo lo detecto, yo lo analizo y yo saco el turno en el coso, ya lo vimos los beneficios todos.» (3prof-36)

Si, como decía Giddens (2000), la culpa resalta en sociedades donde el comportamiento social está regido por preceptos morales, entendemos que estos continúan ligados a la auto-responsabilización del 
ser madres. De este modo, la culpa aparece como la emoción inmediata a la auto-responsabilización por la falta ante lo que hacen -comer lo que les gusta» o ante lo que no -como hacer actividad física ${ }^{6}$ o comer lo que les gusta».

El recorrido biográfico que las mujeres mantienen con el régimen alimentario y el círculo del cuidarse nos permite entender a estas prácticas como una presencia constante en las que ellas pendulan entre la culpa, la falta y la auto-responsabilización, en asociación al desagrado de la propia práctica. La culpa de no seguir el régimen alimentario se une a la auto-responsabilización tanto de llevarlo adelante «individual o familiarmente» como de no hacerlo. Ante esta totalidad de la relación culpa/auto-responsabilización, las mujeres no pueden hacer otra cosa que volver a comenzar el régimen del «cuidarse» buscando evitar la culpa, repitiendo la privación como un castigo auto-impuesto y manteniéndose en un «siempre igual».

A partir de lo expuesto, se entiende que la alimentación de las mujeres está signada por la privación y la culpa: culpa de lo que se comió el fin de semana, culpa de lograr una alimentación familiar saludable, etc. La culpa está unida a la privación en un continuo que funciona tanto como forma de la dieta como castigo de su falta y, de este modo la privación no tiene cortes. Pero lo llamativo es que en este privarse por los otros o auto-privarse, ellas se ven como las responsables de sus hábitos alimentarios que las mantienen en falta. ${ }^{7}$

A continuación, nos centraremos en la vergüenza como anverso de la culpa ligada al comer cotidiano.

\section{La vergüenza}

Mientras S. Freud mantenía que la culpa es una «angustia social» (1989, p.48), otros autores sostienen que «mientras la culpa es un estado de angustia privado, la vergüenza es un estado de angustia público» (Giddens, 2000, p.87). La diferencia principal entre la culpa y la vergüenza es que mientras la culpa tiene que ver con haber llevado adelante una acción incorrecta, la vergüenza está en relación con la mirada de los otros, lo que queda claro es que la culpa y la vergüenza se encuentran íntimamente ligadas.

Para Giddens (1995) los procesos de la modernidad privilegiaron la aparición de la vergüenza por sobre la culpa, ya que «a medida que se rompían las trabas de la tradición y comenzaba a evidenciarse el proyecto reflejo del yo, el centro del escenario pasaba a estar ocupado más por la dinámica de la vergüenza que de la culpa». De este modo, el control y coacción que en la antigüedad se ejercía a partir de la violencia y luego de la represión, con la modernidad, se transformó en un fortalecimiento de los miedos internos. Pero este pasaje de la violencia física externa a la vergüenza «interna» no implicó una disminución de la coerción, sino un posicionamiento de la vergüenza como modo de control que lleva a los individuos a auto-coacciones propias (Elias, 2009, p.500).

Las prácticas del comer se relacionan con la vergüenza a partir del paso de la alimentación de la esfera privada a la pública. En la alimentación en el ámbito laboral, la vergüenza se corresponde con el hecho de realizar en público una práctica privada, sin lugar ni tiempo específico para la misma. Ante este contexto, aparece la vergüenza como la emoción predominante del comer en la oficina.

«Era una fiaca porque no había una cocina, era como que vos comías y todo el mundo, (...) no había paredes entonces todo el mundo se enteraba que vos ibas a comer y a veces como que no daba, porque qué se yo, había gente más grande, no tenés mucha confianza y de tu misma edad que tampoco tenía confianza... y vos pasabas con el pedazo de tarta y el puré. Como que no es algo íntimo, pero a veces te da vergüenza que te vean comiendo o que sepan que vas a comer, primero porque no sé si el olor está molestando o siempre está eso o al menos es algo que siento yo, 'ah, está comiendo' como que queda como que estás perdiendo el tiempo en vez de trabajar. Te pagan para ir a trabajar y vos estás almorzando y perdés el tiempo.» (1jov-27 años)

La vergüenza se respalda en la posibilidad de estar infringiendo un código moral compartido (Scheff, 1988), en este caso el molestar al otro mientras se come en un espacio que no está constituido para tal actividad. 
La vergüenza es un sentimiento propio del ser humano, este existe por y en su cuerpo y la distancia que vivencia entre este cuerpo vivo y la persona espiritual, será la situación que posibilite el surgimiento de la vergüenza (Scheler, 2004). La vergüenza se siente en la vivencia ante la mirada de los otros sobre la oposición entre algo que «debe ser» de algún modo y algo «que es» de uno distinto. La vergüenza produce una distancia entre los otros y la valoración que consideramos nos dan, ya que la vergüenza está ligada al cuerpo subjetivo a partir de la mirada de los otros (Scheff, 1988). Definida de este modo, «la vergüenza emerge ante la percepción de la mirada del-otro, mirada de desagrado que tensionalmente adviene en incomodidad» (Vergara, 2009, p.47) y se da entre el cuerpo subjetivo y el cuerpo social, de modo que el yo subjetivo se ajusta a las condiciones de tiempo/espacio y el cuerpo social se ubica como posibilidad de valoración de los otros.

En este caso, comer se instituye como un acto de carácter compartido, cotidiano pero ligado a lo doméstico y sus prácticas poseen reglas específicas para ser realizadas por fuera. Principalmente, el comer se realiza con otros, no frente a otros. Comer frente a otros deja a las entrevistadas en una situación de inadecuación entre el uso del espacio y las prácticas llevadas adelante en él. En este acto quedan expuestas a la mirada de los otros, y a que «todo el mundo se entere» de los estilos de vida, las prácticas, los gustos y las posiciones sociales reflejadas en la forma de comer, lo que se come, cómo se lo come.

Comiendo en público las entrevistadas quedan expuestas al reclamo del organismo. Esto se liga al asco de exhibir la parte animal de nuestra constitución: tener hambre. De este modo, las prácticas del comer se hacen visibles desde lo físico-orgánico que nos muestra la vulnerabilidad del cuerpo, desde el hambre que se quiere acallar. Y desde el cuerpo subjetivo como yo que se forma a partir de la mirada de los otros dando lugar a un yo que se ubica en la incomodidad y la inadecuación.

Por su parte, la vergüenza se vuelve reguladora de los cuerpos de modo que junto con el desagrado termina reemplazando el castigo físico y la sanción. Al comer en público, sin horarios, en el momento en que se tiene hambre, las entrevistadas quedan ancladas en una respuesta moral, ya que comer frente a otros expone a las mujeres no solo a la inadecuación sino también a los deseos no controlados, a la falta que mantiene sin cierre la búsqueda de un régimen alimentario específico.

«Me siento bien, que estoy haciendo las cosas bien. Estaría mal si comiera facturas todos los días, que antes lo solía hacer, me tentaba, siento que hago las cosas bien, como fruta, agua, siento que estoy bien. Como variado...» (1adm-43 años)

Las prácticas del comer se encuentran organizadas por normas morales, que son sociales y por lo tanto de género y de clase. Siguiendo los aportes de Bordo (2000), entendemos que las mujeres se socializan en una relación con el comer que las ubica en la búsqueda de la privación del placer y del control del comer. En este caso, podemos observar que la entrevistada no solo controla el no tentarse, sino que éste la ubica en el espacio de la moralidad, del otro lado de la vergüenza, de modo que, al privarse sostiene «que hace las cosas bien», lo que la hace «sentirse bien» (Boragnio, 2019b).

Podemos pensar las conexiones entre vergüenza y desagrado, como dos emociones que regulan las relaciones sociales a partir de la coacción individual y privada de los individuos. Elias (2009) indicaba el carácter conflictivo de la vergüenza en el sujeto, en tanto éste se encuentra en la contradicción entre lo que desea y lo que debe, produciendo vergüenza y culpa a partir de las prácticas privativas. En este aspecto, las mujeres deben mostrar equiparación entre lo que deben comer y lo que comen, ya que la vergüenza es la primera emoción que aparece ante la exposición pública de este desfasaje.

Como pudimos observar, las emociones desarrolladas, el asco, la culpa y la vergüenza -A-C-V» se encuentran asociadas a la auto-responzabilización y la privación como modo de darle respuesta al cansancio, la falta y la repetición como estados del sentir de las prácticas del comer cotidianas conformadas por la dieta y las prácticas del dietar. 


\section{A modo de cierre}

En base a lo expuesto en estas páginas, entendemos que las prácticas del comer de las mujeres entrevistadas se estructuran a partir de la relación entre la comida de oficina y un régimen alimentario eligado a lo sano, liviano, ricoe que se articula con las prácticas del dietar a partir del lazo emocional conformado entre el asco, la culpa y la vergüenza.

La vergüenza y el asco son indicadores del juicio moral que está en relación al desagrado y al disgusto, dando como resultado culpa. A su vez, la culpa, en conexión con la falta, lleva a la repetición como única acción posible para evitar la culpa, lo cual reproduce el asco, ya que repitiendo las comidas, los sabores y la dieta, el gusto se satura, al mismo tiempo que las mujeres se privan del gusto y de las energías necesarias. A partir de estas uniones podemos observar que la falta y la culpa estructuran la cotidianeidad de la alimentación de las mujeres entrevistadas.

Es importante remarcar que la alimentación no solo es central en la reproducción y disponibilidad social de los cuerpos, sino que lo orgánico/cognitivo/afectivo se entrelaza en la producción y reproducción de los cuerpos/emociones y en la distribución de la energía corporal y social, como eje principal de la estructuración social. Si bien las entrevistadas dan cuenta de la relación de la alimentación y el estado corporal físico, pareciera que la importancia en la alimentación como energía y reproducción no aparece como una relación concreta.

Ante esta experiencia llevan adelante prácticas del dietar ligadas a la privación como forma de regulación del apetito, de las prácticas y de las formas del cuerpo, en relación a lo que se puede y debe, o no, comer. Esta relación entre las prácticas del dietar como prácticas de privación y la alimentación es central ya que ambas están directamente relacionadas con la reproducción de la energía corporal y social.

Desde las bases de la constitución del capitalismo la privación estructuró la relación entre regulación, sensibilidad y expansión, por lo que los procesos de estructuración se pueden rastrear en la relación entre necesidades, deseos y acción a partir de la mercantilización fetichista de la vida y la desposesión de las energías. La maquinaria extractiva del capitalismo tiene por objetivo la energía en todas sus formas y la regulación de la energía corporal socialmente disponible compone el eje de su reproducción a corto plazo. Esta desposesión no deja al otro solo en condiciones de inacción «sino que también «formatea» heterónomamente la acción» (Scribano, 2010a, p.15). En este sentido, entendemos que el asco, la culpa y la vergüenza (A-C-V), como emociones preponderantes del comer de las mujeres, configuran cuerpos/emociones que se sostienen entre la auto-imposición y la auto-responsabilización, sin cuestionar la privación como eje estructurador del cuidarse.

\section{Notas}

\footnotetext{
${ }^{1}$ En adelante, emplearemos el uso de comillas para destacar y señalar las categorías y conceptos empleados por las mujeres entrevistadas.

${ }^{2}$ Para profundizar sobre estas conexiones ver, Boragnio (2019 c).

${ }^{3}$ Para profundizar en las prácticas de privación de las mujeres entrevistas, ver Boragnio, (2019b).

${ }^{4}$ Esta idea se retomará con mayor profundidad más adelante, en el apartado subtitulado «La culpa«.

${ }^{5}$ «...the paradigm of satietory disgust is more important than all variants of disgust at touching or smelling an objetct at all (...). For satietory disgust emerges at the locus of pleasure itself, where not too little or no pleasure is present, but in fact an excess...» Traducción propia.

${ }^{6}$ «...me daba mucha culpa dejar dos horas a la nena para irme a hacer gimnasia, dije ¿Para qué?, al pedo, prefiero estar con la nena, disfrutar de la nena y, por ende, chau gimnasio, y así estamos (se ríe).» (3jov-28 años)

${ }^{7}$ Entre las entrevistas encontramos reiteradas veces las siguientes frases «siempre culpables» (1jov), «así estamos» (2jov), «muy mal» (3prof), ante la pregunta de cómo se sienten con su alimentación.
} 


\section{Bibliografía}

Bericat Alastuey, E. (2012). Emociones. Sociopedia.isa. doi: 10.1177/205684601261.

Boragnio, A. (2018). Disposable commensality: strategies for the selection of meals in the office. Eureka: Social and Humanities, (5), 16-28. doi: 10.21303/2504-5571.2018.00724.

(2019a). Comer en la oficina: prácticas del comer y emociones de mujeres trabajadoras en el ámbito de la Administración Pública Nacional Argentina. (Tesis doctoral). Universidad de Alicante, España.

(2019b). «Me estoy cuidando»: mujeres, prácticas del comer y política de las sensibilidades. En Bitencourt, S. y Andrade C.B. (comp.), Corpo, Gênero e Cuidados: Perspectivas e desafíos na contemporaneidade (pp. 97-110). Mato Grosso, Brasil: Universidade Federal de Mato Grosso.

(2019c). Producción de subjetividades en el autocuidado alimentario cotidiano. Buenos Aires: Estudios Sociológicos Editora. (En prensa).

Boragnio, A. y Dettano, A. (2019). Emociones, Intervención Social y políticas sociales: el amor maternal en la encrucijada. Azarbe, Revista Internacional de Trabajo Social y Bienestar, (8), 39-48. doi: 10.6018/azarbe.390321.

Bordo, S. (1993). Unbearable weight. Feminism, Western culture and the body. Berkeley: University of California Press.

Elias, N. (2009). El proceso de la civilización. México: Fondo de Cultura Económica.

Figari, C. (2009). Las emociones de lo abyecto: repugnancia e indignación. En Figari, C. y Scribano, A. (comp.), Cuerpos, subjetividades y conflictos: hacia una sociología de los cuerpos y las emociones. Buenos Aires: Fundación Centro de Integración, Comunicación, Cultura y Sociedad - CICCUS, 2009.

Freud, S. (1989). El malestar en la cultura. Buenos Aires: Amorrortu Ed.

Germov, J. y Williams, L. (2008). A Sociology of Food and Nutrition: The Social Appetite. Oxford University Press, New York, USA.

Giddens, A. (1995). La constitución de la sociedad. Buenos Aires: Amorrortu.

(2000). Modernidad e identidad del yo. $3^{\circ}$ edición. Barcelona: Península.

Gracia Arnaiz, M. (2005). Maneras de comer hoy. Comprender la modernidad alimentaria desde y más allá de las normas. Revista Internacional de Sociología (RIS), (40), 159-182. doi: 10.3989/ris.2005.i40.193.

Katz, M. (2010). Comer: práctica individual, práctica social. En Katz, M., Aguirre, P. y Bruera, M. (2010) Comer. Puentes entre la alimentación y la cultura. Buenos Aires: Libros del Zorzal. ISBN: 978-987-599-154-5.

Kolnai, A. (2013). Asco, soberbia, odio. Fenomenología de los sentimientos hostiles. Madrid: Ediciones Encuentro.

Le Breton, D. (2007). El sabor del mundo. Una antropología de los sentidos. Buenos Aires: Nueva Visión Argentina. (2017). El cuerpo herido. Identidades estalladas contemporáneas. Buenos Aires: Topia Editorial.

Menninghaus, W. (2003). Disgust. Theory and History of a Strong Sensation. SUNY series, Intersections: Philosophy and Critical Theory. 
Nussbaum, M., (2004). Hiding from Humanity. Princeton University Press, Princeton.

Quepons Ramírez, (2014). Reseña de Aurel Kolnai, 2013. Asco, soberbia, odio. Fenomenología de los sentimientos hostiles. Revista de Filosofía Open Insight, (5), núm. 8, 175-184. Recuperado de: https://www.redalyc.org/ pdf/4216/421639458011.pdf

RAE- Diccionario de la Real Academia Española. Disponible en: https://www.rae.es/

Rozin, P, J. Haidt, y C.R. McCauley (1999). Disgust: The Body and Soul Emotion. En T. Dalgleish y M. Power (comps.), Handbook of Cognition and Emotion (pp. 429-445), John Wiley, Sussex.

Ryle, G. (1971). Systematically misleading expressions (1932). En Ryle, G. Collected Papers Vol. 2, Collected Essays 1929-1968. London: Hutchinson.

Salles, A. (2010). Sobre el asco en la moralidad. Diánoia, 55(64), 27-45. Recuperado de: http://www.scielo.org.mx/ scielo.php?script=sci_arttext\&pid=S0185-24502010000100002\&lng=es\&tlng=es.

Schachter, S., y Singer, J. (1962). Cognitive, social, and physiological determinants of emotional state. Psychological review, 69(5), 379-399. doi: 10.1037/h0046234.

Scheff, Th. (1988). Shame and conformity: the deference-emotion system. American Sociological Review, 53(3), 395-406. doi: 10.2307/2095647.

Scheler, M. (2004). Sobre el pudor y el sentimiento de vergüenza. Salamanca: Sígueme. Scribano A. (2010a) Primero hay que saber sufrir...!!Hacia una sociología de la 'espera' como mecanismo de soportabilidad social. En Scribano, A. y Lisdero, P. (comp.), Sensibilidades en juego: miradas múltiples desde los estudios sociales de los cuerpos y las emociones. Córdoba. CEA.

(2010b). Cuerpo, emociones y teoría Social Clásica: hacia una sociología del conocimiento de los estudios sociales de los cuerpos y las emociones. En Grosso, J.L y Boito, M.E. (comp). Cuerpos y Emociones desde América Latina. CEA-CONICET: Doctorado en Ciencias Humanas-Facultad de Humanidades - Universidad Nacional de Catamarca. Ebook.

(2012). Sociología de los cuerpos/emociones. Revista Latinoamericana de Estudios sobre Cuerpos, Emociones y Sociedad 4(10), 93-113. Recuperado de: http://www.relaces.com.ar/index.php/relaces/article/view/ 224

(2013). La religión neo-colonial como la forma actual de la economía política de la moral. De prácticas y discursos. Cuadernos de ciencias sociales, 2(2), 1-20. Recuperado de: http://ppct.caicyt.gov.ar/index.php/ depracticasydiscursos/article/view/7062/6302

(2016). Sociología de las emociones en Carlos Marx. Carolina del Norte: Editorial Contracorriente.

Scribano, A. y De Sena, A. (2016). Cuerpos débiles: energías, políticas alimentarias y depredación de bienes comunes. En Martins, P. y de Araújo Silva, M. (org.), Democracia, Pós-desenvolvimiento e gestão de benscomus. Perspectivas da América Latina e do Caribe. Brasil: Editora. pp. 115-128 ISBN: 978-85-3910824-4.

Vergara, G. (2009). Conflicto y emociones. Un retrato de la vergüenza en Simmer, Elias y Giddens como excusa para interpretar prácticas en contextos de expulsión. En Figari, C. y Scribano, A. (comp.), Cuerpos, subjetividades y conflictos: hacia una sociología de los cuerpos y las emociones. Buenos Aires: Fundación Centro de Integración, Comunicación, Cultura y Sociedad - CICCUS, 2009. 
Vigarello, G. (2011). Historia de la obesidad. Metamorfosis de la gordura. Buenos Aires: Nueva Visión.

Von Scheve, C. y Jan Slaby, J. (2019). Emotion, emotion concept. En Slaby, J. \& von Scheve, C. (eds.), Affective Societies: Key Concepts. New York: Routledge.

Wolf, N. (1990). El mito de la belleza. Barcelona: Emece Editores. 